\title{
Os Odontoideum: Report of Eight Cases and Review of the Literature
}

\author{
Bokhary Mahmoud1, Wael Hammad1, Ahmad Abdrabou² \\ ${ }^{1}$ Department of Neurosurgery, Armed Force Hospital Southern Region, Khamis Mushait, Saudi Arabia \\ ${ }^{2}$ Radiology, Armed Force Hospital Southern Region, Khamis Mushait, Saudi Arabia \\ Email: bmmaly@yahoo.co.uk,waelhammad78@yahoo.com
}

How to cite this paper: Mahmoud, B. Hammad, W. and Abdrabou, A. (2020) Os Odontoideum: Report of Eight Cases and Review of the Literature. Open Journal of Modern Neurosurgery, 10, 464-474. https://doi.org/10.4236/ojmn.2020.104047

Received: September 4, 2020

Accepted: October 17, 2020

Published: October 20, 2020

Copyright ( 2020 by author(s) and Scientific Research Publishing Inc. This work is licensed under the Creative Commons Attribution International License (CC BY 4.0).

http://creativecommons.org/licenses/by/4.0/

(c) (i) Open Access

\begin{abstract}
Background: Os odontoideum is a separate odontoid process from the body of the axis. It is a rare anomaly of the craniovertebral junction with evidence of both congenital and acquired causes but the aetiology still debated in the literature. It can lead to instability of the atlantoaxial joint and places the spinal cord at significant risk. Methods: Eight cases of os odontoideum were symptomatic at time of presentation, submitted for general and neurological examination, and investigated with different radiological modalities and managed with surgical fixation and stabilization. These patients followed for one year postoperatively. Results: The study includes six male patients and two female patients with median age 18.7 years. All patients presented with myelopathy and showed clinical evidence of atlantoaxial instability. They submitted for complete radiological investigations (plain $\mathrm{x}$ ray, CT scan and MRI) craniocervical junction. They underwent cervical surgical stabilization, two cases by atlantoaxial arthrodesis with wiring, two atlantoaxial fixation by lateral mass screw one of them with transoral odontoiectomy, two atlantoaxial fixations by a Rosen's Hooks, and two cases craniocervical fixation by Tie frame. Death postoperatively recorded in two patients. Follow-up one year revealed resolution of symptoms in two patients and four patients remained stationary but without deterioration. Conclusion: Os odontoideum is a rare but sometimes lethal abnormality that requires radiological and clinical judgement to ensure the best choice of management and optimum patient's care.
\end{abstract}

\section{Keywords}

Os Odontoideum, Craniocervical Junction Lesions, Atlantoaxial Instability

\section{Background}

The exact incidence of os odontoideum is unknown, but it is probably more 
common than estimated [1]. It is reported that odontoid anomalies are common in patients with Down syndrome, Klippel-Feil syndrome, Morquio syndrome and spondyloepiphyseal dysplasia [2]. It is classified into two types: dystopic and less common orthotopic and this depends on location of the ossicle [3], and its aetiology could be congenital or acquired [4] [5] and the major risk of this pathology is the instability and compression of the spinal cord.

Patients with this condition can be asymptomatic or present with a wide range of neurological dysfunctions.

Os odontoideum can mimic Type I and II odontoid fractures and accurate identification is important to prevent the possibility of incorrect treatment. There is a role for conservative treatment of an asymptomatic incidentally found, radiologically stable and non-compressive os odontoideum. However, surgical treatment has a definitive role in symptomatic cases [6].

The current study presents eight cases of Os odontoideum with discussion of diagnosis, aetiology, radiological investigations and its management.

\section{Methods}

Eight cases of os odontoideum were enrolled in the study from February 2016 to January 2019, diagnosed, treated and followed for one year postoperatively at department of neurosurgery, Armed Force Hospital Southern Region, Saudi Arabia. Inclusion criteria include any patient with radiological evidence of os odontoideum with or without other anomalies. Exclusion criteria include patients not candidate for surgery, claustrophobic patients and patient with cochlear implants or cardiac pacemakers that prevent MRI exam.

All these patients were symptomatic, at time of presentation, they submitted for complete neurological and general examination, with stress on searching for congenital anomalies in the nervous and other systems especially in patients with no history of significant trauma.

All patients underwent plain cervical radiograph (AP and lateral views) and $\mathrm{CT}$ scan of the cervical spine. Images were acquired in axial plane, bone window and then transferred to 3D workstation where sagittal and coronal reformations took place. Patients with neurological manifestations were scanned with MRI to exclude cord compression. Attention was paid to bone anatomy and presence of congenital vertebral anomalies or signs indicating trauma.

These patients were candidates for surgical intervention using different surgical procedures, including interspinous atlantoaxial arthrodesis in 2 cases, fixation using Rosen's Hook in 2 cases, lateral mass screw in 2 cases one of them following transoral odontoiectomy and 2 cases treated with craniocervical fixation from occiput to $\mathrm{C} 2$ using Tie frame.

The patients followed for one year postoperative, they followed clinically and improvement proved in two patients, two patients died and four patients remained stationary without deterioration during follow up period.

Bony fusion confirmed in the survived patients as proved by follow up CT 
scan and lack of motion on dynamic $\mathrm{X}$ rays.

\section{Results}

Characteristics of the eight patients are shown in Table 1. There are six males and two females. The median age of the patients was 18.7 years (range $5-44$ years).

Clinically all patients presented with cervical pain and quadriparesis, 4 cases with sphincteric troubles, 3 cases with paraesthesia and least clinical findings were respiratory troubles in two cases and torticollis in two cases, Table 2, with duration of symptoms ranged from two months to three years.

Findings included the presence of a well-defined, well-corticated ossicle at the anatomical location of the odontoid process (orthotopic type) or elsewhere (dystopic type) that was separated from the body of axis by a gap and MRI revealed compression of the proximal cervical cord (Figures 1-3).

Surgical procedures in these cases done in four forms of stabilization; interspinous atlantoaxial arthrodesis in 2 cases (Figure 4); Rosen's Hook C1 - C2 fixation in two cases (Figure 5), atlantoaxial fixation by lateral mass screw one of

Table 1. Summary of eight patients with os odontoideum.

\begin{tabular}{|c|c|c|c|c|c|c|c|}
\hline $\begin{array}{l}\text { Case } \\
\text { No. }\end{array}$ & $\begin{array}{l}\text { Age } \\
(\mathrm{Y})\end{array}$ & Sex & $\begin{array}{l}\text { Dura. of } \\
\text { symp. }\end{array}$ & Clinical pictures & $\begin{array}{l}\text { History of } \\
\text { trauma }\end{array}$ & Surgi. proced. & Outcome \\
\hline 1 & 16 & M & $6 \mathrm{~ms}$. & Cerv. pain, quadrip., paras., resp. tro., sphinc. tro. & + & $\mathrm{C} 1$ - C2 wiring & Stat. \\
\hline 2 & 19 & $\mathrm{~F}$ & $2 \mathrm{~ms}$. & Cerv. pain, quadrip., resp. tro., sphinc. tro. & + & $\mathrm{C} 1$ - C2 wiring & Died \\
\hline 3 & 12 & M & $18 \mathrm{~ms}$. & Cerv. pain, quadrip., torticollis & - & Rosen's Hook & improved \\
\hline 4 & 17 & M & 3 Ys. & Cerv. pain, quadrip. & - & Rosen's Hook & Stat. \\
\hline 5 & 30 & M & 2 Ys. & Cerv. pain, quadrip., paras., sphinc. tro. & + & Lateral mass screw fixation & Stat. \\
\hline 6 & 7 & M & $1 \mathrm{Y}$. & Cerv. pain, quadrip., paras., sphinc. tro. & + & Tie frame & Stat. \\
\hline 7 & 5 & $\mathrm{~F}$ & $6 \mathrm{~ms}$. & Cerv. pain, quadrip., torticollis & - & Tie frame & Died \\
\hline 8 & 44 & $\mathrm{M}$ & $3 \mathrm{~ms}$. & Cerv. pain, quadrip. & - & $\begin{array}{l}\text { Lateral mass screw fixation } \\
+ \text { transoral odontoide }\end{array}$ & improved \\
\hline
\end{tabular}

M: male, F: female, ms: months, Ys: years, Dura. of symp.: duration of symptoms. Cerv. pain: cervical pain, Quadrip.: quadriparesis, Paras: paraesthesia. Resp. tro: respiratory troubles, Sphinc. tro: sphincteric troubles. Surgi. proced.: surgical procedure, Stat.: stationary. Odontoide: odontoidectomy

Table 2. Clinical presentations in eight cases.

\begin{tabular}{ccccccccc}
\hline & \multicolumn{10}{c}{ Case number } \\
\cline { 2 - 9 } Clinical picture & 1 & 2 & 3 & 4 & 5 & 6 & 7 & 8 \\
\hline Cervical pain & $\times$ & $\times$ & $\times$ & $\times$ & $\times$ & $\times$ & $\times$ & $\times$ \\
Quadriparesis & $\times$ & $\times$ & $\times$ & $\times$ & $\times$ & $\times$ & $\times$ & $\times$ \\
Sphincteric troubles & $\times$ & $\times$ & & & $\times$ & $\times$ & & \\
paraesthesia & $\times$ & & & & $\times$ & $\times$ & & \\
respiratory troubles & $\times$ & $\times$ & & & & & & \\
Torticollis & & & $\times$ & & & & & \\
\hline
\end{tabular}




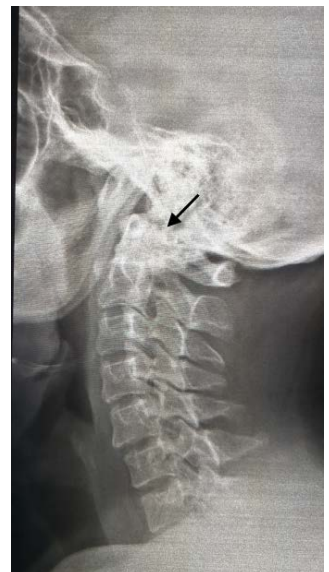

(A)

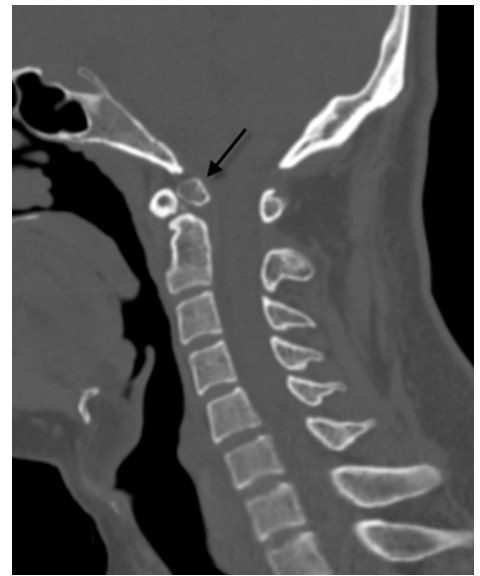

(B)

Figure 1. (A) Plain X-ray, lateral view, and (B) CT scan, showed os odontoideum (black arrows) attached to $\mathrm{C} 1$ (orthotopic type).

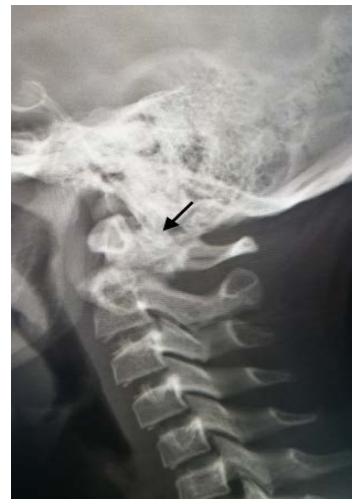

(A)



(B)

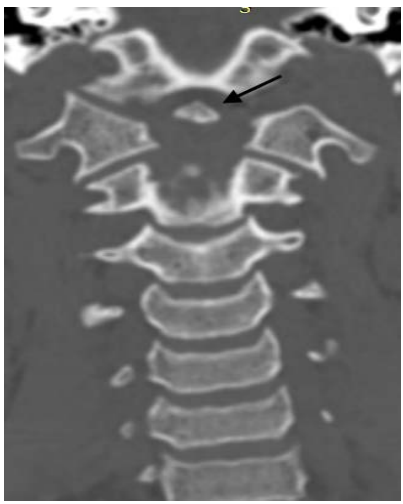

(C)

Figure 2. (A) Plain radiograph of the cervical spine lateral view, (B) sagittal and (C) coronal CT images, of the same patient, revealed an os odontoideum (black arrows) attached to $\mathrm{C} 1$ with wide gap between the os and body of axis (dystopic type).

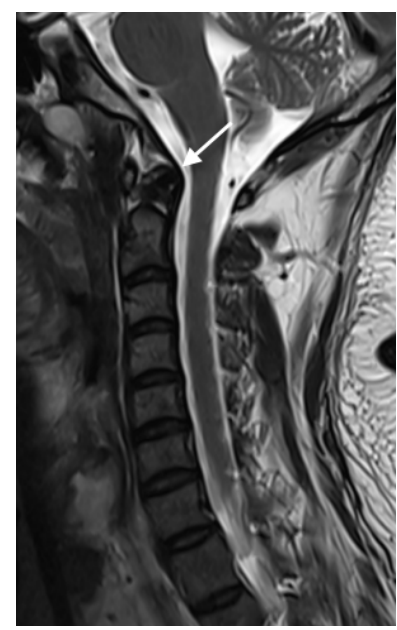

(A)

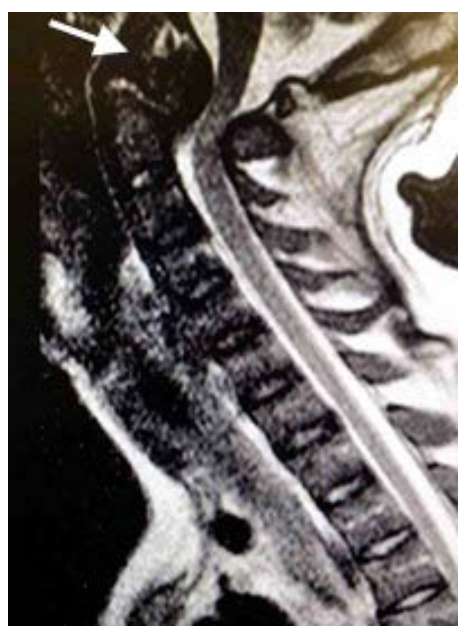

(B)

Figure 3. Sagittal T2 WI MRI show the os odontoideum (white arrows) in stable position (A) and compromising the proximal cervical cord (B). 




Figure 4. Plain X-ray postoperative showed wiring system C1 - C2.
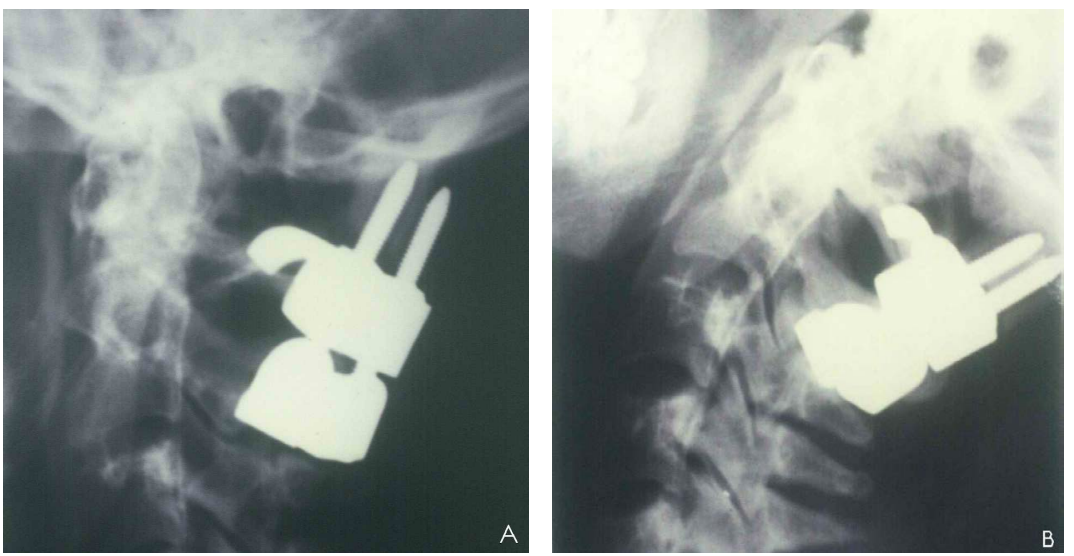

Figure 5. Plain x-ray postoperative showed fixed segment in both flexion and extension with Rosen's Hook in place.

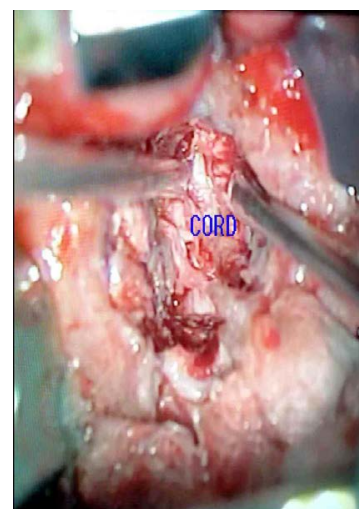

(A)

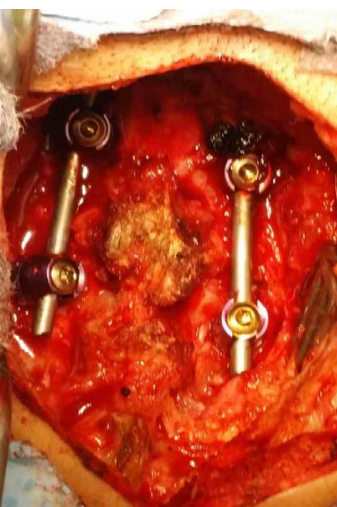

(B)

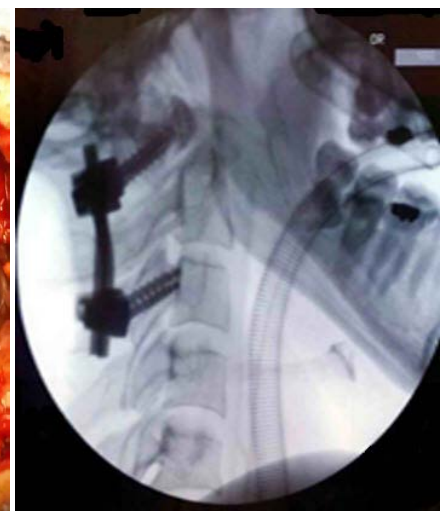

(C)

Figure 6. (A) transoral approach; (B) Lateral mass screw and rods; (C) postoperative $\mathrm{x}$ ray.

them with transoral odontoiectomy (Figure 6), and two cases fixed by craniocervical fixation from occiput to $\mathrm{C} 2$ by Tie frame.

Four patients in this study had history of trauma, two with minor and two with major trauma. 
Fusion confirmed in surgically stabilized patients and defined by a lack of motion on plain x-ray dynamic views with trabeculation of bone between graft and bone. Also confirmed by thin section CT scan through craniocervical junction.

The survived patients followed for at least one year postoperative, they followed by clinical examination and radiology.

Outcome of these patients; four patients remained stationary, two showed resolution of symptoms and improved, in case number 3 , the torticollis disappeared, cervical pain subsided and power in upper and lower limbs returned to normal. Also in case number 8 , this patient had no more cervical pain and power became normal, while the remaining two patients number 2 and 7 died; the first one died one week postoperative from respiratory failure and the second one, he was kept on endotracheal tube and oxygen postoperative but died on next day following surgery.

No patients of those survived deteriorated in the post-operative period of follow up for one year after surgery.

\section{Discussion}

In 1863, separation of the odontoid process from the body of the axis was described in a postmortem specimen, and in 1886, Giacomini coined the term os odontoideum [7].

It is defined as an independent ossicle of variable size with smooth circumferential margins separated from a foreshortened odontoid peg. The ossicle stands apart from the hypoplastic dens and can adopt two anatomic types: orthotopic and dystopic. An ossicle located in the position of the normal odontoid is referred to as orthotopic, and considered dystopic if it appears near the occiput in the area of the foramen magnum. The incidence of os odontoideum is unknown because the lesion is usually asymptomatic [8]

A review of the literature fails to disclose any solid evidence of aetiology of Os Odontoideum [9]. Kirlew et al. [10] published a case of os odontoideum among homozygot twin with fusion of posterior arch of $\mathrm{C} 2$ and $\mathrm{C} 3$.

Also, Yukata et al. [11] reported os odontoideum case in a patient with achondroplesia, and Garg et al. [12] reported a case of os odontoideum associated with bipartite atlas and this can explain the embryological basis of os odontoideum.

But, the high frequency of past history of spinal trauma in cases with os odontoideum suggests the posttraumatic theory. Arnold and Menezes [3] reported a series of 134 cases with os odontoideum 74 patients of them had past history of spinal trauma and 30 patients of these traumatic patients had normal cervical x-ray before age of 4 years, while in a study of Spierings and Braakman [13] only two cases among 37 patients with os odontoideum suffered from evident trauma.

Rregardless of its etiology, Os Odontoideum remains a major compromise to atlanto-axial stability, even under physiological loads in some individuals, plac- 
ing the spinal cord and the vertebral artery at a significant risk of injury [14].

In our cases four patients had definite history of trauma but no old cervical $\mathrm{x}$-rays were available for these patients to be compared with posttraumatic $\mathrm{x}$-ray films.

The median age of the patients involved in this study is 18.7 years, with six males and two females. In a study by Fielding et al. [15] the average age at diagnosis was 18.9 years and the youngest patient was 3 years old with $40 \%$ of these patients their ages were less than 10 years, and in other study done by Arnold and Menezes [3] they studied on 134 patients and they reported that the age ranged from 4 to 58 years and 102 cases of these patients their ages were less than 17 years, with 74 males to 60 females.

The presentation of os odontoideum can vary from an incidental radiographic finding to severe findings of myelopathy, vertebral artery compression, and intracranial manifestations. In a study of Watanabe et al. [16] 10 patients out of 34 cases presented with cervical pain (and or brachialgia). In our patients all of them presented with neck pain, and in the same study, 15 cases out of 34 presented with myelopathy. Quadriparesis recorded in all cases of this study, while sphincteric troubles recorded in 4 patients and 3 patients had paraesthesia.

Jun [17] reported that, myelopathy, including weakness, sensory deficits, sphincteric troubles and respiratory symptoms could be from atlanto-axial subluxation, or compression by granulation tissues around odontoid process. Also, rigidity of the neck and headache [18], reported in os odontoideum cases and in this study, two cases presented with torticollis.

Takauwa et al. [19] reported a case of os odontoideum presented with atlantoaxial dislocation induced vertebral artery occlusion, leading to brain stem infarction, but we had not cases with vertebral artery insufficiency manifestations.

The recent developments on advanced imaging techniques (high-resolution CT scan and MRI) allow more accurate examination of the upper cervical spine [20] and these modalities can confirm the diagnosis and evaluate the degree of atlantoaxial instability.

This anomaly may mimic Type 1 and Type 2 odontoid fractures. Accurate identification is important to prevent the possibility of incorrect treatment [21].

Plain X-ray of the cervical spine should be the first modality in diagnosis of os odontoideum and dynamic flexion and extension radiographs are useful for assessing atlantoaxial stability. CT scan of the cervical spine and craniocervical junction confirm the diagnosis of os odontoideum [22], with typical aspect of the shape of os odontoideum is oval or triangular surrounded by cortex [23].

MRI provides information regarding the spinal cord and the presence of cord signal changes, which in the face of os odontoideum is an absolute indication for surgery. Also MRI should be routinely obtained in the patient presented with neurologic signs or symptoms. In our cases all of them submitted to radiological investigations including plain $\mathrm{x}$ ray, CT scan cervical and craniocervical junction and neural compression confirmed with MRI study. 
Treatment of patients with os odontoideum can be difficult because of the variable and poorly understood natural course of os odontoideum [24]. Watanabe et al. [16] recommended conservative treatment if there is no risk of spinal cord injury, but Stevens et al. [5] reported that, when you have spinal cord compression radiologically with or without signs surgery is mandatory because the reversibility of the clinical presentation is compromised.

Numerous surgical techniques are described for this rare anatomic disorder [25], and according to the American Association of Neurological Surgeons and the Congress of Neurological Surgeons in 2001 the treatment principles for os odontoideum are as follows, in symptomatic patients and in those with C1 - C2 instability, posterior fixation and fusion were suggested, such as $\mathrm{C} 1$ - C2 pedicle screw fixation and fusion or occipitocervical fusion and fixation. For patients with an irreducible dislocation, transoral decompression was suggested [26].

Posterior approach can be done by wiring C1 - C2 [27], screw fixation, or craniocervical fixation [28]. In our cases C1 - C2 wiring used in 2 cases, with ages 16 and 19 years; Rosen's Hook for C1 - C2 arthrodesis used in 2 cases aged 12 and 17 years and Tie frame occipitocervical fusion done in 2 cases aged 7 and 5 years. Bone grafts in these cases were used artificial bone graft. Two cases treated with lateral mass screw fixation, one of them aged 30 years treated only with lateral mass screw and the other patient aged 44 years, his case necessitating odontoidectomy because MRI preoperative showed severe pressure by os odontoideum on craniocervical junction. Three of these cases the initial management was skull traction by crutchfield tong for one week preoperative for realignment of the spine.

Clinically two patients improved and four patients remained stationary. Radiological fusion was defined as bridging bone between $\mathrm{C} 1$ and $\mathrm{C} 2$ for atlantoaxial fusion or between occiput and $\mathrm{C} 2$ for craniocervical fusion.

The prognosis for posterior approach (as used in treatment of our cases), in study of

Spiering and Braakman, [13] reported that, complete disappearance of myelopathic effects in 3 cases and partially in 5 cases out of 16 patients. Also Fielding et al. [15] 96.2\% of their patients improved after posterior approach.

Abumi et al. [29] presented 3 patients with neurovascular complications that were directly due to cervical pedicle screw insertion, and Madawi et al. [30] reported 5 cases of vertebral artery injury and 1 case of temporary cranial nerve palsy among 61 patients who underwent $\mathrm{C} 1-2$ posterior screw fixation. We had not any case complicated with vascular or nervous injury.

\section{Limitation of the Study}

The small number of cases owing to the rarity of the disease was a significant limiting factor. Further studies with a larger number of cases are required for better understanding of the disease, evaluating the radiological role and assessing clinical outcome. 


\section{Conclusions}

Os odontoideum is a rare anomaly of the craniocervical junction, with instability at atlantoaxial joint, the presentation usually with spinal cord compression. Its aetiology remains challenging regarding it is traumatic or congenital anomaly.

The diagnosis of os odontoideum cannot be decided on clinical background only and the radiological investigations remain the mainstay of diagnosis in these cases and it is important for surgical decision.

The neurological deficits usually don't disappear after the surgery of these cases, but the goal is to stop deterioration in these cases. So, post-operative clinical and radiological follow up for at least one year is recommended for such cases.

\section{Conflicts of Interest}

The authors declare no conflicts of interest regarding the publication of this paper.

\section{References}

[1] Dempster, A.G. and Heap, S.W. (1990) Fatal High Cervical Spinal Cord Injury in AN Automobile Accident Complicating Os Odontoideum. The American Journal of Forensic Medicine and Pathology, 11, 252-256. https://doi.org/10.1097/00000433-199009000-00016

[2] Warner, W.C. (2013) Pediatric Cervical Spine. In: Canale, S.T., Beaty, J.H., Ed., Campbell s Operative Orthopaedics, 12th Edition, Elsevir-Mosby, Philadelphia, 16531660. https://doi.org/10.1016/B978-0-323-07243-4.00040-2

[3] Arnold, H. and Menezes, A.H. (1999) Pathogenesis, Dynamics, and Management of Os Odontoideum. Neurosurgical Focus, 6, Article 2. https://doi.org/10.3171/foc.1999.6.6.5

[4] Morgan, M.K., Onofrio, B.M. and Bender, C.E. (1989) Familial Os Odontoideum. Case Report. Journal of Neurosurgery, 70, 636-639. https://doi.org/10.3171/jns.1989.70.4.0636

[5] Stevens, J.M., Chong, W.K., Barber, C., Kendall, B.E. and Crockard, H.A. (1994) A New Appraisal of Abnormalities of the Odontoid Process Associated with AtlantoAxial Subluxation and Neurological Disability. Brain, 117, 133-148. https://doi.org/10.1093/brain/117.1.133

[6] Kaya, A.R., Turkmenoglu, O., Cavusoglu, H., et al. (2005) Os Odontoideum: A Case Report. Turkish Neurosurgery, 15, 157-161.

[7] Pinho, A.R., Moutinho, V.V., Silva, N.P.A., Serdoura, A.F.M., Freitas, J.M.F., Pinto, R.A.P. and Cabral, A.V.T. (2012) Os Odontoideum-Case Report. Colunal Columna, 11, 333-335. https://doi.org/10.1590/S1808-18512012000400018

[8] Ariffin, M.H., Ashfaq, M.M. and Kang, E. (2016) Transtubular Transoral Surgery for Excision of a Dystrophic Os Odontoideum: A Case Report. Malaysian Orthopaedic Journal, 10, 50-52. https://doi.org/10.5704/MOJ.1603.009

[9] Heick, A. (1996) Juvenile Avascular Necrosis of the Odontoid Process. A Review on the Aetiology of Os Odontoideum and Absentia Odontoidei. Danish Medical Bulletin, 43, 363-366.

[10] Kirlew, K.A., Hathout, G.M., Reiter, S.D. and Gold, R.H. (1993) Os Odontoideum in 
Identical Twins: Perspectives on Aetiology. Skeletal Radiology, 22, 525-527. https://doi.org/10.1007/BF00209102

[11] Yukata, K., Katoh, S., Sairyo, K., Matsui, Y., Hamada, Y. and Yasui, N. (2008) Os Odontoideum in Achondroplasia: A Case Report. Journal of Pediatric Orthopaedics $B$, 17, 103-105. https://doi.org/10.1097/BPB.0b013e3282f54a55

[12] Garg, A., Gaikwad, S.B., Gupta, V., Mishra, N.K., Kale, S.S. and Singh, J. (2004) Bipartit Atlas with Os Odontoideum: Case Report. Spine, 29, 35-38. https://doi.org/10.1097/01.BRS.0000106487.89648.88

[13] Spierings, E.L. and Braakman, R. (1982) The Management of Os Odontoideum. Analysis of 37 Cases. The Journal of Bone and Joint Surgery, 64, 422-428. https://doi.org/10.1302/0301-620X.64B4.7096415

[14] Jumah, F., Alkhdour, S., Mansour, S., He, P., Hroub, A., Adeeb, N., Hanif, R., Mortazavi, M.M., Tubbs, R.S. and Nanda, A. (2017) Os Odontoideum. A Comprehensive Clinical and Surgical Review. Cureus, 9, e1551.

https://doi.org/10.7759/cureus.1551

[15] Fielding, J.W., Hensinger, R.N. and Hawkins, R.J. (1980) Os Odontoideum. The Journal of Bone and Joint Surgery, 62, 376-383. https://doi.org/10.2106/00004623-198062030-00007

[16] Watanabe, M., Toyama, Y. and Fujimura, Y. (1996) Atlantoaxial Instability in Os Odontoideum with Myelopathy. Spine, 21, 1435-1439.

https://doi.org/10.1097/00007632-199606150-00007

[17] Jun, B.Y. (1999) Complete Reduction of Retro-Odontoid Soft Tissue Mass in Os Odontoideum Following the Posterior C1-C2 Transarticular Screw Fixation. Spine, 24, 1961-1964. https://doi.org/10.1097/00007632-199909150-00017

[18] Hensinger, R.N., Fielding, J.W. and Hawkins, R.J. (1978) Congenital Anomalies of the Odontoid Process. Orthopedic Clinics of North America, 9, 901-912.

[19] Takauwa, T., Hiroi, S., Hasegawa, H., Hurukawa, K., Endo, S. and Shimamura, T. (1994) Os Odontoideum with Vertebral Artery Occlusion. Spine, 19, 460-462. https://doi.org/10.1097/00007632-199402001-00015

[20] Nikouei, F., Rastegar, K., Andalib, A. and Sabbaghan, S. (2016) A Symptomatic Displaced Os Odontoideum: A Case Report. Shafa Orthopedic Journal, 3, e4785. https://doi.org/10.17795/soj-4785

[21] Altun, I. and Yuksel, K.Z (2016) An Uncommon Case Mimicking Cervical Trauma: Os Odontoideum. Case Report. Turkish Journal of Emergency Medicine, 17, 22-24. https://doi.org/10.1016/j.tjem.2016.08.001

[22] French, H.G., Burke, S.W., Roberts, J.M., Johnston, C.E., Whitecloud, T. and Edmunds, J.O. (1987) Upper Cervical Ossicles in Down Syndrome. Journal of Pediatric Orthopaedics, 7, 69-71. https://doi.org/10.1097/01241398-198701000-00014

[23] Holt, R.G., Helms, C.A., Munk, P.L. and Gillespy, T. (1989) Hypertrophy of C1 Anterior Arch: Useful Sign to Distinguish Os Odontoideum from Acute Dens Fracture. Radiology, 173, 207-209. https://doi.org/10.1148/radiology.173.1.2781009

[24] Klimo, P., Kan, P., Rao, G., Apfelbaum, R. and Brockmeyer, D. (2008) Os Odontoideum: Presentation, Diagnosis, and Treatment in a Series of 78 Patients. Journal of Neurosurgery Spine, 9, 332-342. https://doi.org/10.3171/SPI.2008.9.10.332

[25] Reilly, C.W. and Choit, R.L. (2006) Transarticular Screws in the Management of C1-C2 Instability in Children. Journal of Pediatric Orthopaedics, 26, 582-588. https://doi.org/10.1097/01.bpo.0000230337.26652.55 
[26] Wu, X.H., Wood, K.B., Gao, Y., Li, S., Wang, J., Ge, T., Zhao, B., Shao, Z.W., Yang, S.H. and Yang, C. (2018) Surgical Strategies for the Treatment of Os Odontoideum with Atlantoaxial Dislocation. Journal of Neurosurgery Spine, 28, 131-139. https://doi.org/10.3171/2017.5.SPINE161211

[27] Griswold, D.M., Albright, J.A., Schiffman, E., Johnson, R. and Southwick, W. (1978) Atlanto-Axial Fusion for Instability. The Journal of Bone and Joint Surgery, 60, 285-292. https://doi.org/10.2106/00004623-197860030-00002

[28] Brecknell, J.E. and Malham, G.M. (2008) Os Odontoideum: Report of Three Cases. Journal of Clinical Neuroscience, 15, 295-301. https://doi.org/10.1016/j.jocn.2006.07.022

[29] Abumi, K., Shono, Y., Ito, M., Taneichi, H., Kotani, Y. and Kaneda, K. (2000) Complications of Pedicle Screw Fixation in Reconstructive Surgery of the Cervical Spine. Spine, 25, 962-969. https://doi.org/10.1097/00007632-200004150-00011

[30] Madawi, A.A., Casey, A.T., Solanki, G.A, Tuite, G., Veres, R. and Crockard, H.A. (1997) Radiological and Anatomical Evaluation of the Atlantoaxial Transarticular Screw Fixation Technique. Journal of Neurosurgery, 86, 961-968.

https://doi.org/10.3171/jns.1997.86.6.0961 